\title{
Modelling and Determination of Physico-Chemical and Morphological Properties of Microencapsulated Red Amaranth Powder
}

(Date received: 14.12.12/Date accepted: 09.09.13)

\author{
Pik Han Chong ${ }^{1}$, Mohammad Gulzarul Aziz ${ }^{2}$, Yus Aniza Yusof ${ }^{3}$, Naim Mohammad Nazli", \\ Nyuk Ling Chin ${ }^{5}$, Sharifah Kharidah Syed Muhammad \\ ${ }^{1,2,3,4,5}$ Faculty of Engineering, Department of Process and Food Engineering, Universiti Putra Malaysia, \\ ${ }^{6}$ Faculty of Food Science and Technology, Department of Food Science, Universiti Putra Malaysia

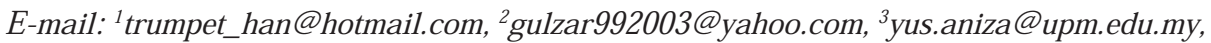 \\ ${ }^{4}$ nazli@eng.upm,edu.my, ${ }^{5}$ chinnl@eng.upm.edu.my, ${ }^{6}$ kharidah@putra.upm.edu.my
}

\section{ABSTRACT}

Amaranth betacyanin, responsible for a red or violet colour, is extracted from Amaranthus gangeticus by using the water extraction method and microencapsulated by spray drying. The physicochemical and morphological properties of microencapsulated betacyanins are assessed as influenced by the inlet temperature and the maltodextrin concentration. The process was conducted using a mini spray dryer and maltodextrin is used as an encapsulating agent. Central composite design is applied and thirteen experiments are carried out. The responses are betacyanin retention, moisture content, water activity, particle densities, particle size, colour values and antioxidant activity. The quadratic effect of the inlet temperature is determined to be positive on betacyanin retention whereas the antioxidant is affected by the linear change of maltodextrin concentration. The moisture content and water activity of spray-dried betacyanin powders are insignificantly affected by inlet temperature and maltodextrin concentration individually. Only the effect maltodextrin concentration is found to have a significant effect on colour value. Particle densities and sizes are slightly affected by the process conditions studied.

Keywords: Amaranth, Colour Stability, Natural Colourant, Pitaya, Spray Drying Modelling

\subsection{INTRODUCTION}

The current increased trend of using natural colourants in the food and pharmaceutical industry has attracted the attention of researchers to find new types and sources of natural pigments. The major advantage of using natural colourants is their functionality besides their colouring potential. Functionally they improve the nutritional quality of foods due to their potential role in human health as natural antioxidant [1]. Chlorophylls, carotenoids, anthocyanins and betalains are the common and widely studied natural pigments. Betalains, a nitrogenous vacuolar pigment, is a promising novel colourant with potential good health effects and has gained much research focus [2]. Betacyanin, water soluble in nature, is a type of betalain responsible for a red or violet colour [3]. A potential natural source of betacyanins is the red beet that is extensively used worldwide. Literature reports a few other potential sources of betacyanins such as cactus pear $[4,5]$, pitaya [6, 7] and amaranth [8]. The betacyanin content of the Amaranthus species, the extraction and production of powder by spray drying were reported by Cai and Corke [9] and Cai et al. [8]. The antioxidant potential, cooking stability and application of amaranthus betacyanins in model food systems has also been studied [10]. Among the literature reports, only a few discuss spray drying of amaranthus betacyanin extract into powder form. There is only one report by Cai and Corke [9] on the production and properties of amaranthus betacynins by spray drying. However, systemic analysis using any statistical design technique was not included in that report.

Microencapsulation by spray drying is a useful technique widely applied in the food, pharmaceutical and chemical industries to stabilize the pigments and the antioxidant activity in solid form $[5,11,12]$. The microencapsulation process can be simply explained as a solid matrix (such as maltodextrin or acacia gum) which dissolved in water and the core materials such as food ingredients are dispersed into it. The encapsulation of food ingredients is achieved by rapid solidification caused by water evaporation during spray drying [12]. Since the ratio of core and coating material and drying temperature are the most critical factors for the microencapsulation of pigments and their bioavailability and stability, a systematic analysis of the effect of these factors on the responses is crucial. The popular class of statistical tools used for the modelling and analysis of problems where a response of interest is influenced by several variables is the Response Surface Methodology (RSM) [13]. Fitting and analyzing response surfaces are greatly facilitated by the proper choice of experimental design and a popular design used for complex processes is Central Composite Design (CCD). In this study the spray drying process of Amaranthus gangeticus betacyanins is systematically analyzed by using response surface methodology with two factors, namely, spray drying inlet temperature and carrier concentration against several responses with maltodextrin as a coating material.

\subsection{MATERIALS AND METHODS}

\subsection{Raw Materials}

A $15 \mathrm{~kg}$ of red amaranth (Amaranthus gangeticus) was purchased from the Pasar Borong, Seri Kembangan, Selangor Darul Ehsan, 
Malaysia. It was cleaned by removing the root, and soil as well as rinsing in tap water. After that it was stored in the a freezer at $-20^{\circ} \mathrm{C}$.

\subsection{Betacyanin Extraction and Spray Drying}

Betacyanin from Amaranthus gangaticus was extracted by water extraction following the method described by Cai et al. [14] with a simple modification. Before the water extraction, the frozen samples were cut into small pieces, which therefore exposed a greater surface area to facilitate extraction. The betacyanin extract was purified by centrifugation (Kubota 2010, Japan) followed by vacuum filtration (Labber Uni-Crown, Taiwan) and concentrated up to total soluble solids 6 as determined by a pocket refractometer (Atago, Japan) under reduced pressure using a rotary vacuum evaporator (Heidolph Laborata 4001 efficient, Germany). Maltodextrin DE10 was used as the coating agent for spray drying. Wall materials (MD) were dispersed in water (6-34\%) and finally made up to a volume of $200 \mathrm{~mL}$ with constant stirring. The wall material was previously swollen in distilled water for $12 \mathrm{~h}$. About $10 \%$ concentrated pigment extracts were added to the mixture and homogenized for each preparation with a homogenizer (WiseMixTM Homogenizer HG15A, Malaysia) at $10000 \mathrm{rpm}$ for $5 \mathrm{~min}$. The homogenized suspension then was ready for spray drying. The resulting solutions were fed to a laboratory scale spray drier (SD-05 England). The spray drier was operated at an inlet temperature ranging from $132^{\circ} \mathrm{C}$ to $188^{\circ} \mathrm{C}$ according to the experimental design. The air flow, the rate of feeding and nozzle size were $18 \mathrm{~m}^{3} / \mathrm{h}, 10 \mathrm{ml} / \mathrm{min}$ and $0.7 \mathrm{~mm}$, respectively and controlled to be the same for all the runs. The powders obtained were stored to exclude light and were kept at $-20^{\circ} \mathrm{C}$ until analyzed.

\subsection{Experimental Design}

A rotatable central composite design (CCRD) constituted by 13 experiments was used (Table 1). The design consist of three level full factorial design $(+1,-1)$, superimposed by the centre point $(0,0)$, and star points $(+\alpha,-\alpha)$. The central composite design was made rotatable by the choice of $\alpha$ and for two factors the value of $\alpha$ is 1.414 [15].
The independent variables considered were the temperature of drying $\left(140^{\circ} \mathrm{C}\right.$ to $\left.180^{\circ} \mathrm{C}\right)$ and wall materials (10 to $30 \%$; ratio of core materials to coating materials from $1: 1$ to $1: 3$ ) for maltodextrin. The response variables were the efficiency of betacyanins encapsulated, their total antioxidant activity and colour value. The moisture content, water activity, density, particle size and shape of produced powder produced were also assessed as response parameters. The variables studied and their effects on responses are shown in Table 2. The behaviour of the system is displayed as a regression equation which is fitted to the data. Equation (1) for the fitted model is shown below:

$\mathrm{y}=\lambda_{0}+\lambda_{1} \mathrm{~T}+\lambda_{2} \mathrm{C}+\lambda_{11} \mathrm{~T}^{2}+\lambda_{22} \mathrm{C}^{2}+\lambda_{12} \mathrm{TC}$

where $\mathrm{y}$ is the response, $\lambda_{0}$ is the interception coefficient, $\lambda_{1}$ and $\lambda_{2}$ are linear terms, $\lambda_{11}$ and $\lambda_{22}$ are quadratic terms, $\lambda_{12}$ is an interaction term, $\mathrm{T}$ is the inlet temperature and $\mathrm{C}$ is the carrier concentration.

The analysis of variance, test for the lack of fit, determination of regression coefficients, generation of three dimensional graphs was carried out using Design Expert 8.

\subsection{Analysis of Physicochemical and Morphological Properties of Powder}

The physicochemical properties of the powder were determined by the methods as described by Ng et al. [1]. The moisture content of the powder was determined by using a moisture analyzer (Ohaus MB45, Switzerland). The water activity of powder was measured by using a water activity meter (FA-ST/lab, GBX Instrumentation Scientifique, France). The colour of the powder was measured by using a colour reader (CR-10, Konica Minolta Sensing America's Ltd, Ramsey, USA). The absolute, tap and bulk densities of the powder were measured. A gas pycnometer (AccuPyc II 1340, Micromeritics, Norcross, USA) was used to determine the absolute density of the powder. Bulk density was measured by dividing the mass of powder by the volume occupied with the powder in a cylinder of known volume. Tapped density was measured by weighing $5 \mathrm{~g}$ of powder in a $10 \mathrm{~mL}$ graduated cylinder and vibrating until a steady volume was reached. The

Table 1: Variables and their levels for central composite rotatable design (CCRD)

\begin{tabular}{|c|c|c|c|c|c|}
\hline Variable & & & Level & & \\
\hline \multirow{2}{*}{ Inlet temperature $\left({ }^{\circ} \mathrm{C}\right)$} & -1.414 & -1 & 0 & +1 & +1.414 \\
\hline & 132 & 140 & 160 & 180 & 188 \\
\hline
\end{tabular}

Maltodextrin

Concentration $(\%)$

6

10

20

30

34 
Table 2: Experiments of two factor CCRD and experimental responses

\begin{tabular}{|c|c|c|c|c|c|c|c|c|c|c|}
\hline IT $\left({ }^{\circ} \mathrm{C}\right)$ & $\begin{array}{l}\text { MD } \\
(\%)\end{array}$ & BR (\%) & MC (\%) & $\mathbf{a}_{\mathrm{w}}$ & $\begin{array}{c}\text { True } \\
\text { density } \\
\left(\mathrm{kg} / \mathrm{m}^{3}\right) \pm \\
\text { std }\end{array}$ & $\begin{array}{c}\text { Tapped } \\
\text { density } \\
\left(\mathrm{kg} / \mathrm{m}^{3}\right) \pm \mathrm{std}\end{array}$ & $\begin{array}{c}\text { Bulk } \\
\text { density } \\
\left(\mathrm{kg} / \mathrm{m}^{3}\right) \pm \\
\text { std }\end{array}$ & $\begin{array}{c}\text { Particle } \\
\text { size }(\mu \mathrm{m})\end{array}$ & $a^{*}$ & $\mathrm{IC}_{50}(\mathrm{mg} / \mathrm{ml})$ \\
\hline 160 & 20 & 81.72 & $5.06 \pm 0.12$ & $0.29 \pm 0.01$ & $1455 \pm 2$ & $429 \pm 10$ & $327 \pm 16$ & $7.63 \pm 0.08$ & $13.51 \pm 0.07$ & 2.70 \\
\hline 160 & 6 & 76.11 & $5.24 \pm 0.16$ & $0.30 \pm 0.01$ & $1467 \pm 2$ & $417 \pm 0$ & $295 \pm 18$ & $5.85 \pm 0.03$ & $17.44 \pm 0.03$ & 0.70 \\
\hline 160 & 20 & 82.38 & $5.24 \pm 0.06$ & $0.34 \pm 0.02$ & $1402 \pm 7$ & $455 \pm 0$ & $328 \pm 25$ & $7.46 \pm 0.07$ & $13.58 \pm 0.02$ & 3.60 \\
\hline 160 & 20 & 77.90 & $4.81 \pm 0.17$ & $0.33 \pm 0.01$ & $1393 \pm 1$ & $438 \pm 5$ & $339 \pm 23$ & $11.06 \pm 0.09$ & $14.15 \pm 0.04$ & 2.70 \\
\hline 180 & 30 & 55.57 & $4.39 \pm 0.21$ & $0.29 \pm 0.02$ & $1431 \pm 4$ & $483 \pm 15$ & $349 \pm 14$ & $9.34 \pm 0.07$ & $11.98 \pm 0.06$ & 4.80 \\
\hline 132 & 20 & 56.24 & $6.37 \pm 0.05$ & $0.45 \pm 0.00$ & $1476 \pm 10$ & $406 \pm 18$ & $358 \pm 26$ & $7.88 \pm 0.03$ & $13.11 \pm 0.03$ & 2.90 \\
\hline 140 & 10 & 70.85 & $5.00 \pm 0.15$ & $0.29 \pm 0.01$ & $1478 \pm 1$ & $401 \pm 16$ & $307 \pm 11$ & $6.09 \pm 0.02$ & $15.02 \pm 0.03$ & 1.40 \\
\hline 160 & 34 & 66.16 & $4.85 \pm 0.08$ & $0.27 \pm 0.02$ & $1429 \pm 6$ & $442 \pm 12$ & $349 \pm 14$ & $10.26 \pm 0.02$ & $12.26 \pm 0.09$ & 7.60 \\
\hline 160 & 20 & 77.90 & $5.77 \pm 0.19$ & $0.33 \pm 0.02$ & $1503 \pm 0$ & $442 \pm 12$ & $324 \pm 18$ & $8.62 \pm 0.12$ & $14.03 \pm 0.04$ & 2.60 \\
\hline 188 & 20 & 68.55 & $4.51 \pm 0.13$ & $0.30 \pm 0.01$ & $1384 \pm 6$ & $417 \pm 0$ & $278 \pm 0$ & $9.21 \pm 0.02$ & $14.34 \pm 0.02$ & 2.80 \\
\hline 180 & 10 & 60.98 & $5.51 \pm 0.12$ & $0.33 \pm 0.01$ & $1416 \pm 14$ & $417 \pm 0$ & $273 \pm 9$ & $6.85 \pm 0.03$ & $16.03 \pm 0.03$ & 1.30 \\
\hline 160 & 20 & 72.61 & $6.13 \pm 0.16$ & $0.43 \pm 0.00$ & $1448 \pm 3$ & $417 \pm 0$ & $326 \pm 6$ & $7.85 \pm 0.04$ & $13.83 \pm 0.06$ & 2.90 \\
\hline 140 & 30 & 58.97 & $6.01 \pm 0.29$ & $0.42 \pm 0.02$ & $1443 \pm 2$ & $461 \pm 10$ & $366 \pm 16$ & $9.48 \pm 0.04$ & $12.07 \pm 0.06$ & 4.20 \\
\hline
\end{tabular}

particle size of the powder was measured by using a particle size analyzer (Malvern Mastersizer 2000, Malvern Instrument Ltd, UK). Particle morphology was investigated using scanning electron microscopy (S-3400N, Hitachi, Japan), It was evaluated at $5 \mathrm{kV}$ with magnifications of 1000x and 5000x. The betacyanin concentration of powder was determined by using a spectrophotometer (DR 2800 Spectrophotometer, HACH, Colourado, USA) as described by Lim et al. [7]. Antioxidant activity was determined in accordance with the 2,2-diphenyl-1picryl hydrazyl (DPPH) method described by Amin et al. [10]. TROLOX was used as a standard and the results were expressed as $\mathrm{IC}_{50}$. All the analyses were done in triplicate and reported as mean \pm standard deviation.

\subsection{RESULTS AND DISCUSSION}

\subsection{Analysis of Response Surfaces}

The response data of betacyanin retention, moisture content, water activity, true density, tapped density, bulk density, particle size, redness (a-value) and antioxidant properties of the powder produced as influenced by inlet temperature and maltodextrin concentration are presented in Table 2. Analysis of the responses data for the response surface design is done and a summary of the regression coefficients for the coded second-order polynomial, the and values and the determination of coefficients for all the responses is shown in Table 3.

Analysis of variance (ANOVA) is performed to assess the significance of the model in terms of adequacy and fitness of the resulting equations. The correlation measure for the testing of goodness of fit of the regression equation is $R^{2}(\mathrm{Adj})$. The value of $\mathrm{R}^{2}$ (Adj) for the fitted models of betacyanin retention, antioxidant, redness, moisture content, bulk density and particle size show satisfactory results. It is also evident from the ANOVA table of the regression model that the models are quite significant, which is indicated by the higher calculated alue and a very low probability value. The variation of data around the fitted model is also indicated by the Lack of Fit. The Lack of Fit for the fitted models of these responses is not significant, indicating that the experimental data fitted to the model. In the case of the significance of the lack of fit, it is considered that the data does not fit well. However, the $\mathrm{R}^{2}$ (Adj) values in the case of water activity, true density and tapped density are quite low. This indicates that the correlations between the observed and predicted values are very poor and unable to fit the polynomial equation.

Table 3: Coefficient values and $R^{2}$ of proposed models

\begin{tabular}{|c|c|c|c|c|c|c|c|}
\hline Factors & $\lambda_{0}$ & $\lambda_{1}$ & $\lambda_{2}$ & $\lambda_{11}$ & $\lambda_{22}$ & $\lambda_{12}$ & $\mathbf{R}^{2}$ \\
\hline $\begin{array}{l}\text { Betacyanin } \\
\text { retention }\end{array}$ & -510.0071 & 7.3414 & 0.3046 & -0.0234 & -0.0498 & 0.0081 & 0.7833 \\
\hline IC50 & -0.4777 & 0.0036 & 0.1378 & - & - & - & 0.9173 \\
\hline value & 14.9877 & 0.0161 & -0.1771 & - & - & - & 0.8635 \\
\hline Moisture content & 0.6851 & 0.0299 & 0.4177 & - & - & -0.0027 & 0.6314 \\
\hline $\mathrm{a}_{\mathrm{w}}$ & -0.0536 & 0.0024 & 0.0346 & - & - & -0.0002 & 0.4472 \\
\hline True density & 1662.9273 & -1.2757 & -0.9218 & - & - & - & 0.3848 \\
\hline Tapped density & 338.7971 & 0.3347 & 2.0169 & - & - & - & 0.5355 \\
\hline Bulk density & 435.7567 & -1.0259 & 2.6421 & - & - & - & 0.8743 \\
\hline Particle size & 2.7453 & 0.0156 & 0.1515 & - & - & - & 0.6513 \\
\hline
\end{tabular}




\subsection{Effect on Betacyanin Retention, Redness and Antioxidant Activity}

The percentage betacyanin retention is the percentage of the betacyanin content in the powder relative to the total betacyanin content in the feed. Figure 1(a) represents a graphical presentation of the regression equation termed as a response surface plot obtained using Statgraphics Centurian. The relation between the betacyanin retention (response) as affected by factors (inlet temperature and maltodextrin concentration) are clearly demonstrated by this presentation. Initially the betacyanin retention was slightly increased with increasing inlet temperature as well as the ratio of coating agents and extract up to the optimum point and then again decreased again. Lower and higher values both of these factors a have negative effect on the betacyanin retention. Between the two factors, the change of inlet temperature is more sensitive than carrier concentration for the variation of betacyanin retention. This is in agreement with the findings published by other researchers. According to Cai and Corke [9], betacyanin degradation increases with increasing drying air temperature and beyond $180^{\circ} \mathrm{C}$ spray drying of betacynin pigments is not feasible. Saenz et al. [5] reported that the recovery of pulp betacynins of cactus pear is $100 \%$ whereas ethanol extract is only $62 \%$ during microencapsulation with maltodextrin (DE 10). According to the report, a higher temperature is attributed as the reason for a higher loss of pigments and the pure compound is highly sensitive to spray drying temperature compared to the conjugate form such as pulp. Concerning the negative effect of the extreme microencapsulation concentration, the lower yield due to higher feed viscosity at the higher carrier concentration can result in a lower recovery of pigments [9]. On the other hand, a lower concentration can cause incomplete encapsulation of betacyanin in the drying chamber as it is lost before transforming from droplets into powder.

Figure 1(c) shows the response plot of redness of the encapsulated powder as influenced by maltodextrin concentration and drying temperature. As shown in Figure 1(c), redness is linearly changed with changing maltodextrin concentration and has a good fitness of model with an $\mathrm{R}^{2}$ value of 0.86 . With increasing maltodextrin content, redness decreases indicating a higher amount of betacyanin compounds being encapsulated. Powders produced with a low maltodextrin concentration give a higher $a^{*}$ value with very low yield of powder having a very high hygroscopicity (data not shown). Since the betacyanins became concentrated during drying at a low carrier concentration, the redness of the powder thus increased. The highest value of redness found in this study is 17.44 , which is lower than that reported by Cai and Corke [9] for amaranth and Saenz et al. [5] for cactus pear. This might be due to the variation of the content of extract in the feed.

Antioxidant was expressed as $\mathrm{IC}_{50}$ meaning the concentration of powder that scavenges 50\% DPPH. A lower $\mathrm{IC}_{50}$ indicates higher antioxidant activity. Figure 1(b) illustrates a graphical presentation of the response surface plot for the antioxidant activity. For the changes of independent variable inlet temperature, there is almost no effect on antioxidant concentration. On the other hand, antioxidant concentration is linearly changed with changing carrier concentration or corecoating ratio indicating carrier concentration as the major factor affecting the antioxidant of the encapsulated betacyanin. With increasing carrier concentration, antioxidant activity is decreased. This is because a lower carrier concentration is unable to encapsulate the active compounds and thus results in a concentrated antioxidant. Thus, the amount of powder required to scavenge $50 \%$ of free radicals is lower, which results in a higher antioxidant activity. The presence of higher surface betacyanins in a low concentration of maltodextrin might also be a vital reason. During the microencapsulation of bioactive compounds of cactus pear pulp using maltodextrin, the effect of inlet temperature is found insignificant at $<\quad$ [5]. Couto $e$ a. [16] reported the extract feed rate exerted a positive nonlinear effect whereas the interaction between the inlet temperature and extract feed rate resulted in strong negative effect on the antioxidant activity of spray dried rosemary extracts.

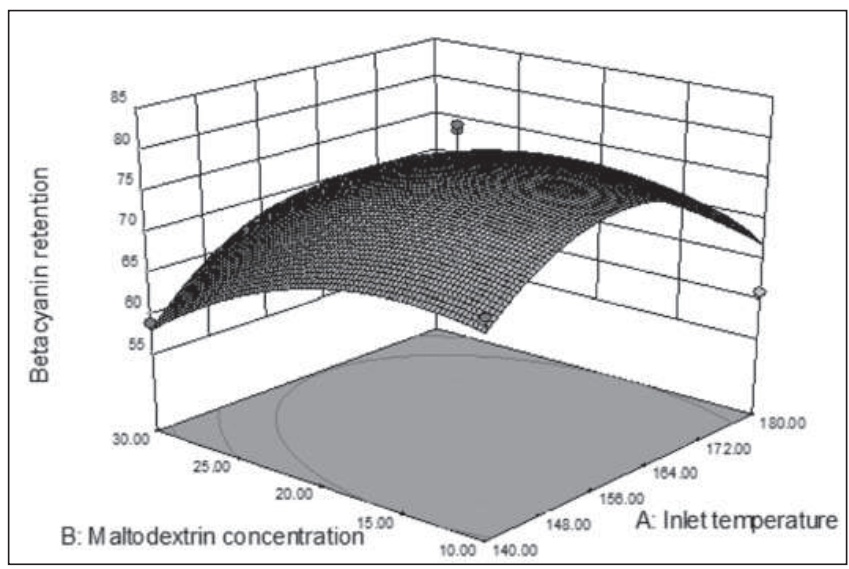

(a)

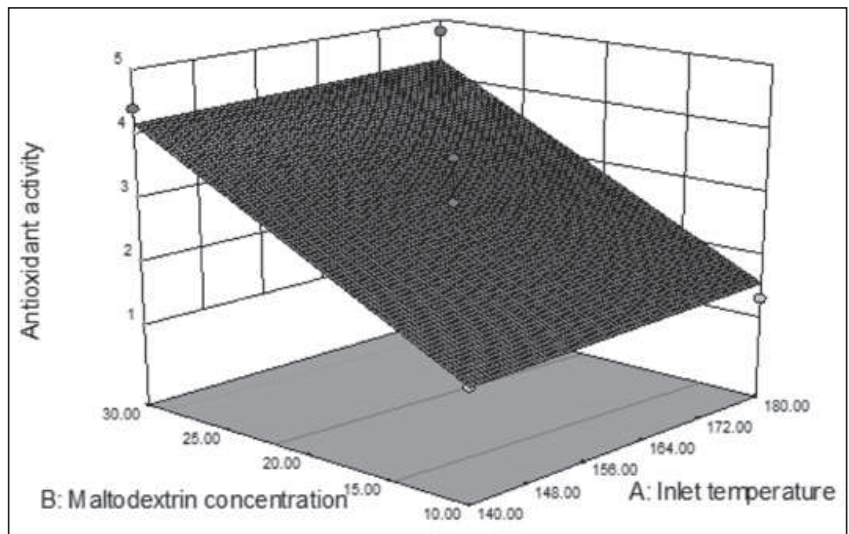

(b)

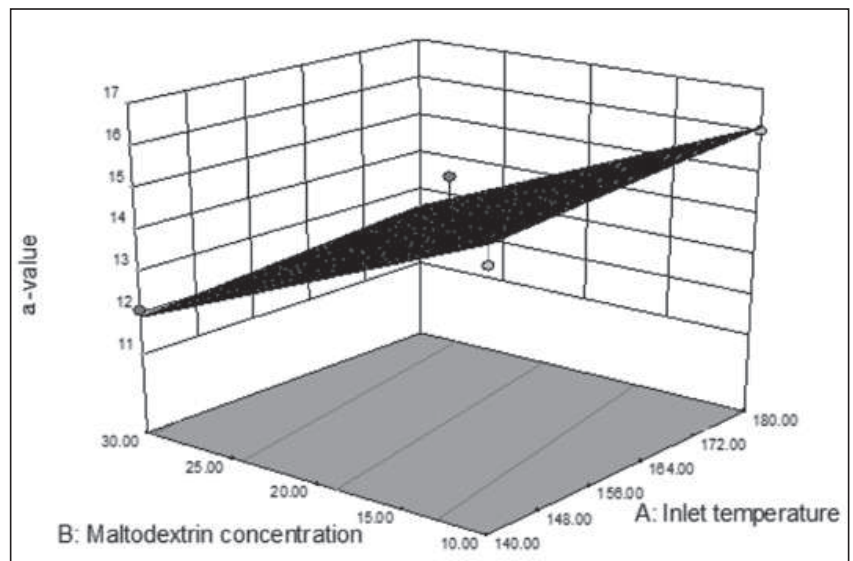

(c)

Figure 1: Response surface plot showing relation between (a) betacyanin retention, (b) antioxidant activity and (c) redness (a-value) as affected by inlet temperature and maltodextrin concentration

Journal - The Institution of Engineers, Malaysia (Vol. 74, No. 2, December 2013) 


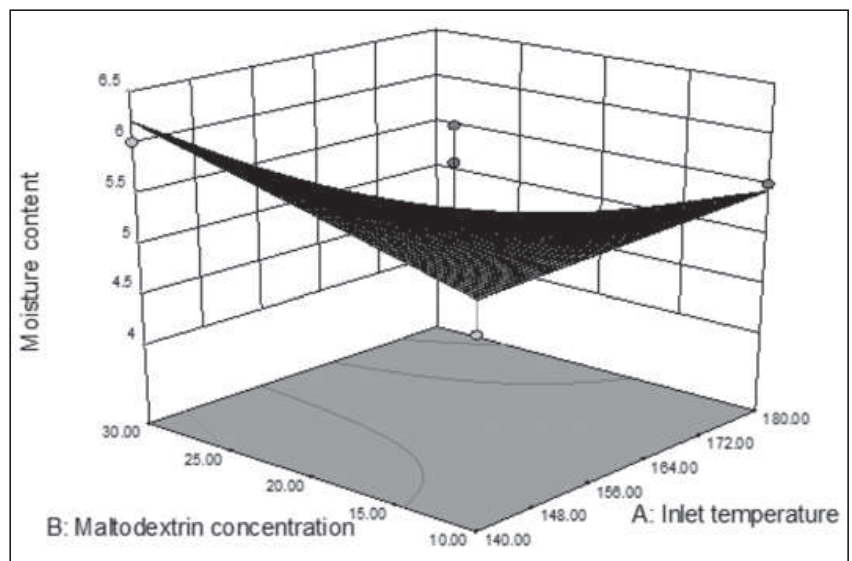

(a)

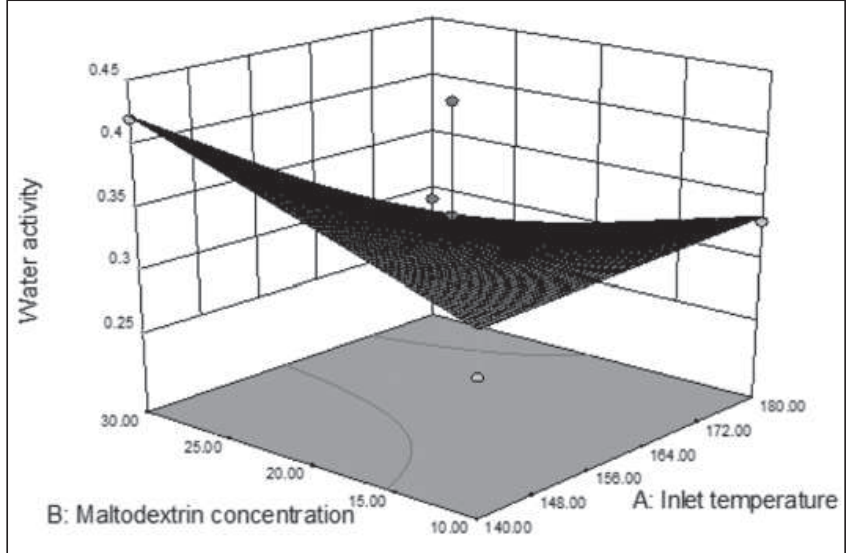

(b)

Figure 2: Response surface plot showing relation between the (a) moisture content and (b) water activity as affected by inlet temperature and maltodextrin concentration

\subsection{Moisture Content and Water Activity}

The response plots of moisture content and water activity of the amaranth powder thus produced at different inlet temperatures and maltodextrin concentrations are shown in Figure 2. The powder produced by spray drying possesses moisture content of between 4.39 to $6.37 \%$. This water content is sufficient to make the food powder microbiologically safe. The range of moisture content is similar to spray dried pitaya fruit powder as obtained by $\mathrm{Ng} e \mathrm{a}$. [1]. However, the changes of moisture in the case of all treatments are much closer. The principles of spray drying might play a vital role in the case of drying of suspensions containing a low amount of almost pure compounds. Moisture evaporated in the drying chamber during spray drying can be explained by droplet drying. In the first stage of drying, the majority of moisture is removed from the surface of liquid droplets. The second stage of drying takes place when there is no more moisture from the surface and a crust was formed. At that moment the moisture removed from the core of the crust moves to the surface by diffusion and during this stage the moisture loss is limited. As shown in Figure 2 and by ANOVA, the moisture content and water activity are little affected by the inlet temperature and maltodextrin concentration individually. Their interactions have a positive effect. With increasing both factors, the moisture content and water activity decreases. However, the effect of inlet temperature is found to be much more dominant

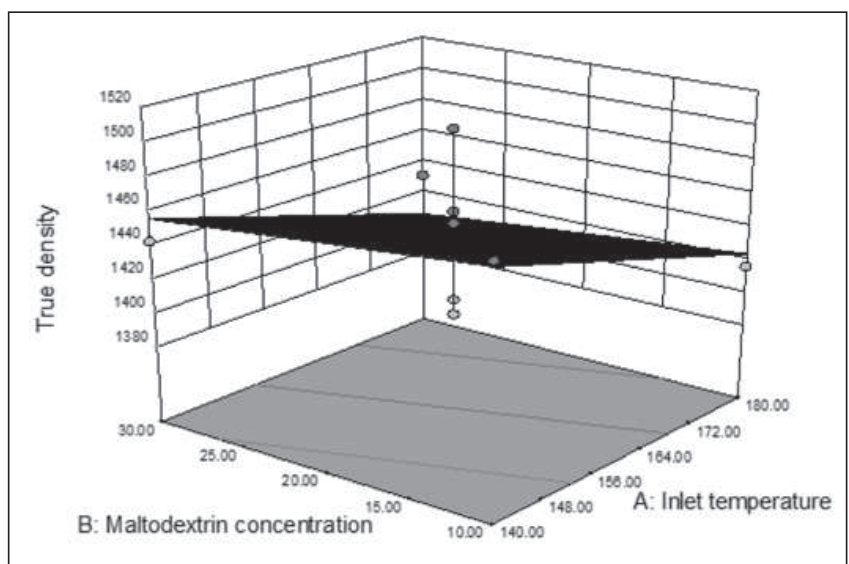

(a)

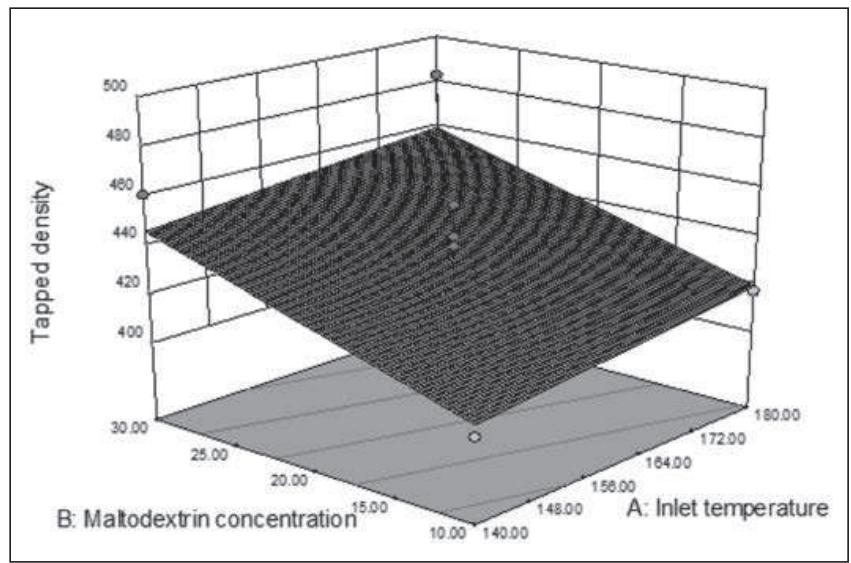

(b)

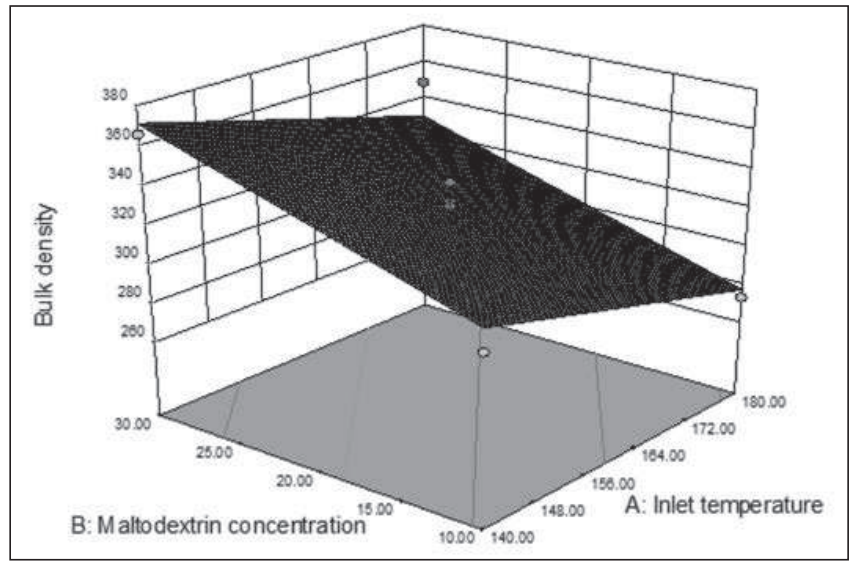

(c)

Figure 3: Response surface plot showing relation between (a) true density, (b) tapped density, and (c) bulk density as affected by inlet temperature and maltodextrin concentration

than the of maltodextrin concentration. According to Quek $e$ a . [17] at a higher inlet temperature the rate of heat transfer to the particles is greater, which provides a great driving force for moisture evaporation. Finally, powders with reduced moisture content are formed. The moisture content of the powder so produced is slightly decreased during the variation of maltodextin concentration which might be due to the increase in the total soluble solids with increasing maltodextrin concentration, [18]. Since the range of change of moisture content is very marginal, this individual factor is not considered to have any significant affect other than interaction. 


\subsection{Densities}

Different types of density are analyzed and the response plots shown in Figure 3. Among the densities, the bulk density is influenced significantly by both the factors whereas the carrier concentration has a significant effect on the tapped density and temperature also affects the true densities as revealed from ANOVA analysis. Interestingly, all densities can be fitted to the linear model. As shown in Figure 3, true density changes with changing inlet temperature, tapped density with carrier concentration whereas bulk density changes with the changing of both the factors. In the case of bulk density of the encapsulated powder, carrier concentration influences the bulk density positively whereas temperature influences negatively. The true density among the formulations ranges from $1384 \mathrm{~kg} /$ $\mathrm{m}^{3}$ to $1503 \mathrm{~kg} / \mathrm{m}^{3}, 400.67 \mathrm{~kg} / \mathrm{m}^{3}$ to $482.67 \mathrm{~kg} / \mathrm{m}^{3}$ for tapped density, and $273 \mathrm{~kg} / \mathrm{m}^{3}$ to $366.33 \mathrm{~kg} / \mathrm{m}^{3}$ for the bulk density. True density excludes the open pores and closed pores of the powder, having the highest value compared to tapped density which only excludes open pores, followed by bulk density which includes both pores.

The inlet temperature is inversely proportional to the true density and bulk density. This is due to the low inlet temperature which causes a low drying rate and the ratio of surface-volume for the spray-dried powder is also decreased and thus a high true density as well as bulk density is obtained. Additionally, the concentration of maltodextrin can also affect the true as well as bulk density. When the inlet temperature was fixed to $160^{\circ} \mathrm{C}$, an increased maltodextrin concentration increases the solid content, resulting in higher densities [9].

\section{Particle Size}

The response surface of particle size as influenced by the factors studied is shown in Figure 4. ANOVA analysis reveals that only the carrier concentration significantly influences the particle size of the microencapsulated betacyanin powder. As shown in Figure 4 , with increasing maltodextrin concentration the particle size increases. Although the inlet temperature insignificantly affects particle size, a slight increase in particle size is observed with increasing inlet temperature. This is possibly due to a high inlet temperature causing high swelling. Another reason is that the high inlet temperature exhibits a fast drying rate which produces the structure early with limited shrinkage of particles and results in a bigger particle size [19]. The particle size is greatly affected by the maltodextrin concentration and this might be related to feed viscosity. The mean liquid droplet size is larger with a high maltodextrin concentration that causes a high feed viscosity during atomization which thus produces larger particles after spray drying [20].

As shown in Figure 4(b), the mean particle size of the powder produced with lower carrier content has a larger size compared to that of a higher content. The powder produced by $34 \%$ maltodextrin (MD) content possesses the highest mean particle size (10.24), followed by $20 \% \mathrm{MD}(8)$ and the lowest mean particle size (5.85) is shown by the powder containing only $6 \% \mathrm{MD}$ at a fixed temperature of $160^{\circ} \mathrm{C}$. Tonon $e$ a. [21] reported similar findings for spray-drying of acai pulp by adding maltodextrin within the range of $10 \%$ to $30 \%$.

\section{Colour Properties}

Table 4 represents the colour parameters of spray-dried powder with different formulations. Before spray drying, the colour

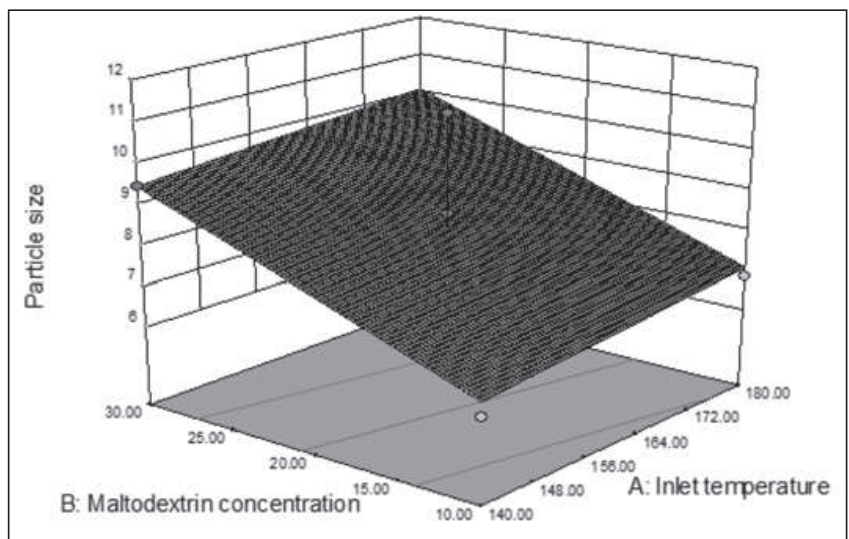

(a)

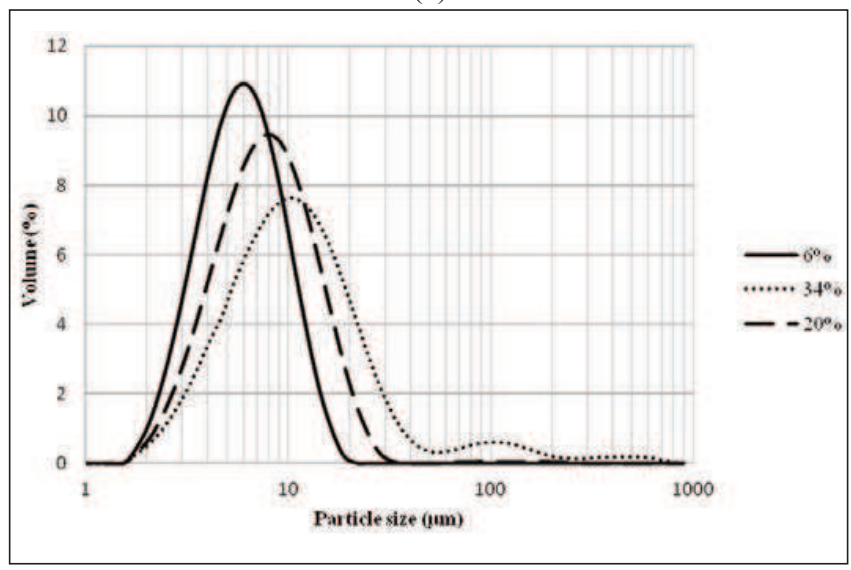

(b)

Figure 4: (a) Response surface plot showing relation between particle size as affected by inlet temperature and maltodextrin concentration, (b) mean particle size of powder produced by different $M D$ concentration at a fixed inlet temperature of $160^{\circ} \mathrm{C}$

parameters for concentrated red amaranth extracts $L^{*}, a^{*}, *, H^{\circ}$ and $*$ are $25.08,4.16,0.46,0.11$ and 4.18, respectively. After spray drying, an obvious increase in values is observed for $L^{*}, a^{*}$ and *. One-way ANOVA unpaired t-test is carried out for $L^{*}$, $a^{*}$ and *. A higher $L^{*}$ indicates higher lightness. The lightness after spray drying is contributed by the addition of whitish maltodextrin. The highest $L^{*}$ is 84.20 due to the highest amount of maltodextrin added. The range of $L^{*}$ is from 80.85 to 81.99 for maltodextrin concentration of $20 \%$, which is considered to be closed to each other, thus no significant differences $(>0.05)$ are observed as Run 1 compared to Run 6 and Run 9, Run 3 compared to Run 9 and Run 12, Run 6 compared to Run 9 and Run 12, Run 9 compared to Run 12, as well as Run 10 compared to Run 12. There are also no significant differences ( $>0.05)$ noticed when Run 5 compared to Run 8 and Run 13 (maltodextrin concentration $30 \%-34 \%$ ). The $a^{*}$ value is also influenced by the maltodextrin concentration. The highest $a^{*}$ value found is 17.44. A low maltodextrin concentration gave a higher $a^{*}$ value as less powder is produced and the betacyanins become concentrated, thus increasing the redness. The majority of $a^{*}$ value among all formulations are found significant differences $(<0.05)$. However, the formulations from middle point $\left(160^{\circ} \mathrm{C}\right.$ inlet temperature, $20 \%$ maltodextrin concentration) do not show significant differences ( >0.05) in Run 1 and 3, Run 4 and 9, Run 9 and 12 . No significant differences $(>0.05)$ are also observed 
Table 4: Colour parameters of formulated spray-dried powder

\begin{tabular}{|c|c|c|c|c|c|c|c|}
\hline Run & $\begin{array}{c}\text { Inlet } \\
\text { temperature } \\
\left({ }^{\circ} \mathrm{C}\right)\end{array}$ & $\begin{array}{c}\text { Maltodextrin } \\
\text { concentration } \\
(\%)\end{array}$ & $\mathbf{L}^{*}$ & $a^{*}$ & $\mathbf{b}^{*}$ & $\mathbf{H}^{\circ}$ & $C^{*}$ \\
\hline 1 & 160 & 20 & $81.99 \pm 0.08$ & $13.51 \pm 0.07$ & $-0.93 \pm 0.03$ & 356.06 & 13.54 \\
\hline 2 & 160 & 6 & $76.13 \pm 0.15$ & $17.44 \pm 0.03$ & $-1.23 \pm 0.02$ & 355.97 & 17.48 \\
\hline 3 & 160 & 20 & $81.62 \pm 0.06$ & $13.58 \pm 0.02$ & $-1.03 \pm 0.04$ & 355.66 & 13.62 \\
\hline 4 & 160 & 20 & $80.85 \pm 0.05$ & $14.15 \pm 0.04$ & $-1.58 \pm 0.09$ & 353.63 & 14.24 \\
\hline 5 & 180 & 30 & $84.14 \pm 0.06$ & $11.98 \pm 0.06$ & $-1.25 \pm 0.05$ & 354.04 & 12.05 \\
\hline 6 & 132 & 20 & $81.90 \pm 0.02$ & $13.11 \pm 0.03$ & $-1.26 \pm 0.03$ & 354.51 & 13.17 \\
\hline 7 & 140 & 10 & $79.08 \pm 0.04$ & $15.02 \pm 0.03$ & $-1.25 \pm 0.04$ & 355.24 & 15.07 \\
\hline 8 & 160 & 34 & $84.20 \pm 0.07$ & $12.26 \pm 0.09$ & $-0.93 \pm 0.05$ & 355.66 & 12.29 \\
\hline 9 & 160 & 20 & $81.87 \pm 0.13$ & $14.03 \pm 0.04$ & $-1.77 \pm 0.01$ & 352.81 & 14.14 \\
\hline 10 & 188 & 20 & $81.15 \pm 0.07$ & $14.34 \pm 0.02$ & $-1.25 \pm 0.04$ & 355.02 & 14.39 \\
\hline 11 & 180 & 10 & $77.96 \pm 0.09$ & $16.03 \pm 0.03$ & $-0.95 \pm 0.04$ & 356.61 & 16.05 \\
\hline 12 & 160 & 20 & $81.49 \pm 0.14$ & $13.83 \pm 0.06$ & $-0.60 \pm 0.01$ & 357.52 & 13.84 \\
\hline 13 & 140 & 30 & $83.94 \pm 0.04$ & $12.07 \pm 0.06$ & $-1.36 \pm 0.03$ & 353.57 & 12.15 \\
\hline
\end{tabular}

in Run 5 and 8, Run 5 and 13, Run 8 and 13, explained by similar maltodextrin content among them. * represents yellowness of the powder. There are unclear significant differences from one-way ANOVA unpaired t-test. For the hue angle $H^{\circ}$, a pure redness is characterized by $0^{\circ}$ or $360^{\circ}$. After spray drying, all the $\mathrm{H}^{\circ}$ values are slightly lower than $360^{\circ}$, ranging from $352.81^{\circ}$ to $357.52^{\circ}$. However, the redness of the powders so produced is ensured as the $H^{\circ}$ values are still near to $360^{\circ}$. Chroma * is related to colour purity. The * value shows improvement from 4.18 to a range of 12.05 to 17.48 after spray drying.

\section{Powder Shape/Morphology}

SEM micrographs of the powder produced for different inlet temperatures and MD concentrations are shown in Figure 5. The morphology of the spray-dried powder by SEM with different maltodextrin concentrations $(6 \%, 20 \%, 34 \%)$ and inlet temperatures $\left(132^{\circ} \mathrm{C}, 160^{\circ} \mathrm{C}, 188^{\circ} \mathrm{C}\right)$ are presented as the top and bottom row of Figure 5, respectively.

A range of sizes is observed, which is common for spray drying. Furthermore, it is obvious that most of the powder presented has a spherical shape, with some uneven spherical shapes. Tonon $e$ a. [21] pointed out that a higher inlet temperature produces a higher drying rate and results in a smooth surface rather than a wrinkled surface. As shown in Figure 5, the optimum spherical shape is produced for an inlet temperature of $160^{\circ} \mathrm{C}$ with a maltodextrin concentration of $20 \%$. It is evident from Figure 5 (bottom) that the surface of the powder produced at $132^{\circ} \mathrm{C}$ is quite smooth whereas the surface is highly wrinkled for the powder produced at $188^{\circ} \mathrm{C}$ even when adding the same amount of MD (20\%). The inlet air temperature is found to have great influence on the shape of the powder rather than that of maltodextrin concentration.

\section{Multiple Optimization and Model Validation}

An optimum response surface model is generated based on the response surface of betacyanin retention, antioxidant activity as well as the $a^{*}$ value. Desirability is used as the response. The optimum value of desirability is 0.706 . Figure 6 illustrates the desirability of the response surface on the inlet temperature and maltodextrin concentration. Table 5 shows the optimum value for factors and responses from multiple responses. In other words, at an inlet temperature of $165.0^{\circ} \mathrm{C}$ with a concentration of $18.84 \%$ exhibits the highest desirability value of 0.706 . The optimum value for betacyanin retention, $\mathrm{IC}_{50}$ and $a^{*}$ is $78.66 \%, 2.8 \mathrm{mg} / \mathrm{ml}$ and 14.35 , respectively. Optimization can be achieved by either minimizing or maximizing the response. The betacyanin retention as well as $a^{*}$ value should be maximized, whereas the $\mathrm{IC}_{50}$ value should be minimized. However, due to the consideration for a properly encapsulated betacyanin pigment, the $\mathrm{IC}_{50}$ value is targeted to be a value of $2.8 \mathrm{mg} / \mathrm{ml}$ instead of being minimized.

Table 6 represents a comparison of responses (betacyanin retention, $\mathrm{IC}_{50}$ and $\mathrm{a}^{*}$ ) between the optimum values and the experimental data for the validation studies. The experimental data for the betacyanin retention, $\mathrm{IC}_{50}$ value and $a^{*}$ value is $79.38 \%$, $3.0 \mathrm{mg} / \mathrm{ml}$ and 13.63 , respectively, which are remarkably close to the predicted optimum values. In conclusion, the experimental data obtained for the validation studies fit to the proposed model, at an inlet temperature of $165.0^{\circ} \mathrm{C}$ with an $18.84 \%$ maltodextrin concentration.

\subsection{CONCLUSION}

The physicochemical and morphological properties of microencapsulated betacyanin powder are found to be highly influenced by the inlet air temperature and maltodextrin concentration during spray drying. The quadratic effect is found significant in betacyanin retention meaning a higher microencapsulation of betacyanin extract can be obtained around the middle of both of the factors. MD concentration is found to be a major factor affecting the antioxidant, particle size, shape and densities of the powder, whereas moisture, water activity and true density are mostly affected by temperature. For the multiple response optimization under the validation studies, the results show that the data obtained experimentally fits to the predicted optimum values. The model for spray drying at inlet 


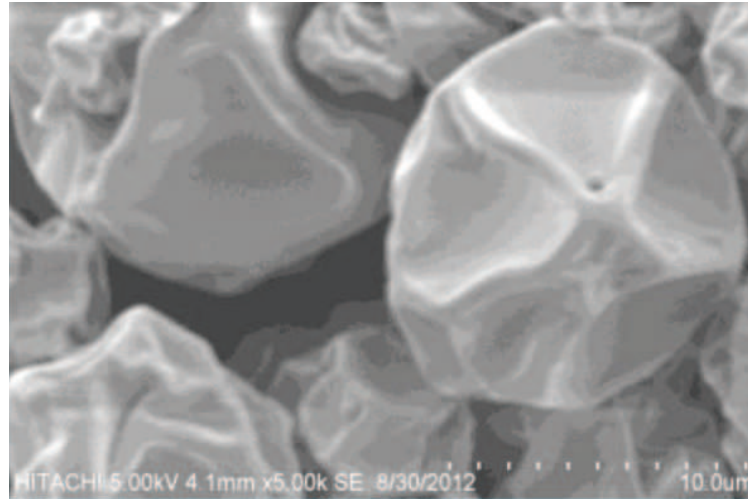

$6 \%)$

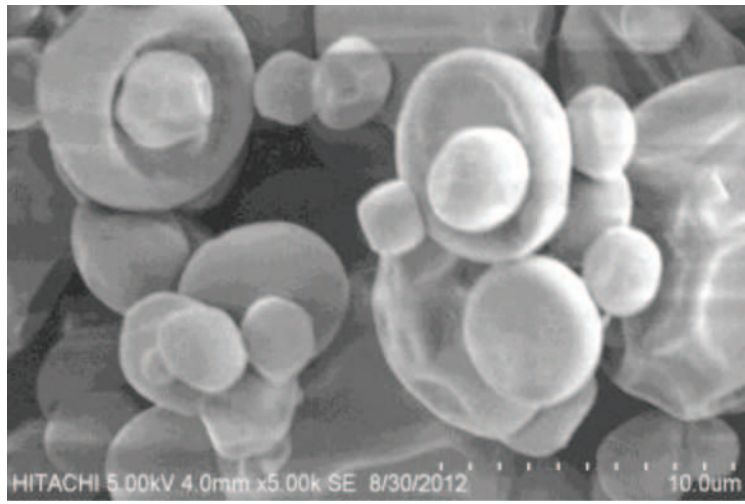

$(20 \%)$

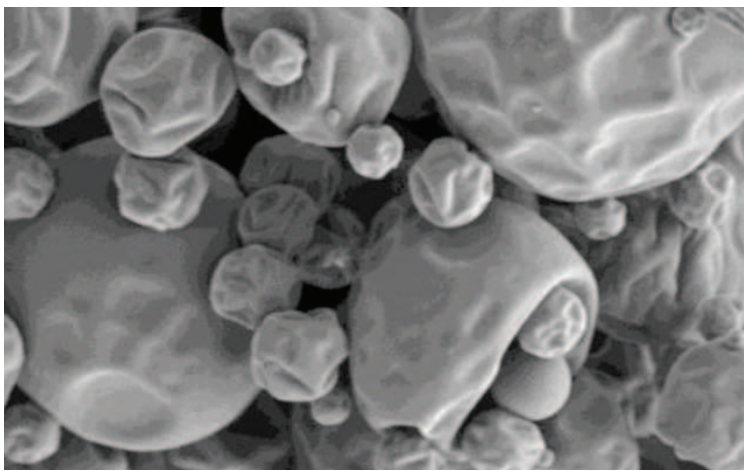

$(34 \%)$

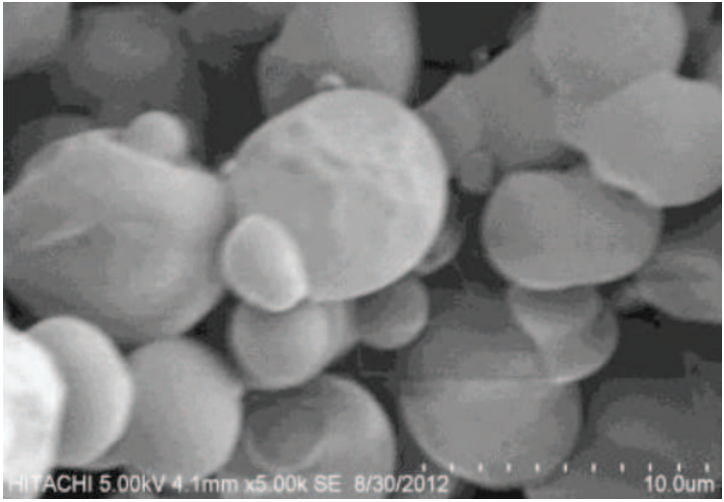

$\left(132^{\circ} \mathrm{C}\right)$

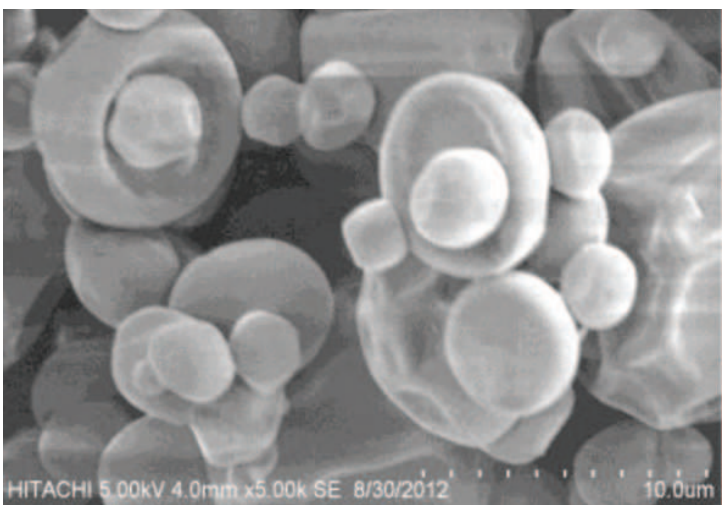

$\left(160^{\circ} \mathrm{C}\right)$

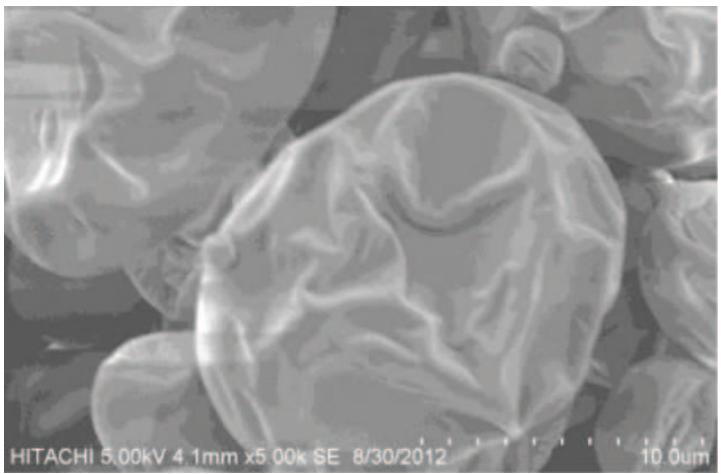

$\left(188^{\circ} \mathrm{C}\right)$

Figure 5: Morphology of spray-dried powder by SEM with different maltodextrin concentrations $(6 \%, 20 \%, 34 \%)$ at a fixed inlet temperature of $160^{\circ} \mathrm{C}$ (left) and with varying inlet temperatures $\left(132^{\circ} \mathrm{C}, 160^{\circ} \mathrm{C}, 188^{\circ} \mathrm{C}\right.$ ) for a fixed $\mathrm{MD}$ concentration of $20 \%$ (right)

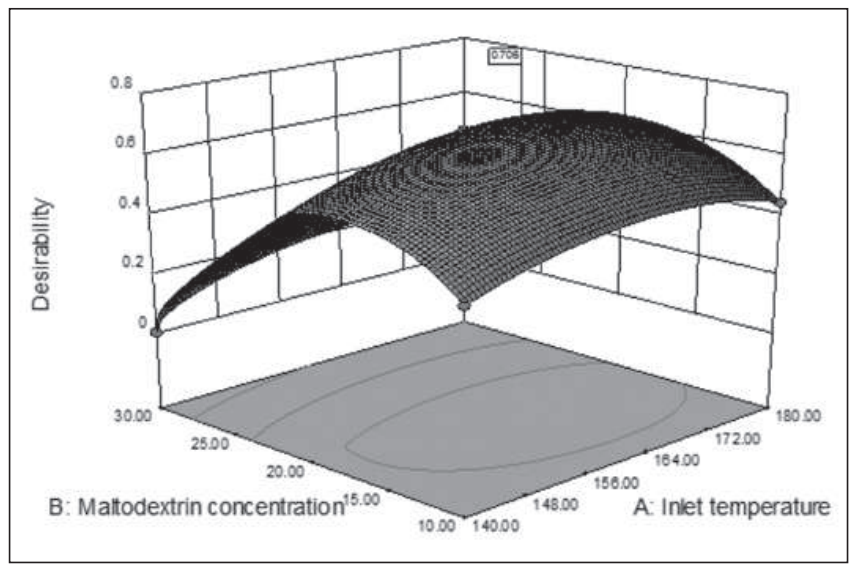

Table 5: Optimum value for factors and responses from multiple responses

\begin{tabular}{cccccc}
\hline Factors & \multicolumn{5}{c}{ Responses } \\
\hline $\begin{array}{c}\text { Inlet } \\
\text { temperature } \\
\left({ }^{\circ} \mathrm{C}\right)\end{array}$ & $\begin{array}{c}\text { Maltodextrin } \\
\text { concentration } \\
(\%)\end{array}$ & $\begin{array}{c}\text { Betacyanin } \\
\text { retention } \\
(\%)\end{array}$ & $\begin{array}{c}\mathrm{IC50} \\
(\mathrm{mg} / \mathrm{ml})\end{array}$ & $\begin{array}{c}\mathrm{a}^{*} \\
\text { value }\end{array}$ & Desirability \\
165.0 & 18.84 & 78.66 & 2.8 & 14.35 & 0.706 \\
\hline
\end{tabular}

Figure 6: Desirability of response surface on inlet temperature, maltodextrin concentration and $a *$ value. 
Table 6: Comparison of responses between optimum values and the experimental data for the validation studies

\begin{tabular}{cccc}
\hline \multicolumn{4}{c}{ Responses } \\
\hline & Betacyanin retention & $\mathrm{IC}_{50}(\mathrm{mg} / \mathrm{ml})$ & $*$ value \\
& $(\%)$ & 2.8 & 14.35 \\
$\begin{array}{c}\text { Optimum value } \\
\text { Experimental } \\
\text { data }\end{array}$ & 78.66 & 3.0 & 13.63 \\
\hline
\end{tabular}

\section{REFERENCES}

[1] L.T. Ng, P.H. Chong, Y.A. Yusof, N.L. Chin, R.A. Talib, S. Taip Farah, M.G. Aziz, Physicochemical and Nutritional Properties of Spray-dried Pitaya Fruit Powder as Natural Colorant. , Vol. 21(3), pp. 675-682, 2012.

[2] H.M.C. Azeredo, Betalains: properties, sources, applications, and stability - a review. $J$ Vol. 44, pp. 2365-2070, 2009.

[3] D. Strack, T. Vogt, W. Schliemann, Review. Research advances in betalain research.

, Vol. 62, pp. 247-269, 2003.

[4] R. Castellar, J.M. Obon, J.A. Fernández-López, The isolation and properties of a concentrated red-purple betacyanin food colourant from Opuntia stricta fruits. $J$ , Vol. 86, pp. 122-128, 2006.

[5] C. Saénz, S. Tapia, J. Chávez, P. Robert, Microencapsulation by spray drying of bioactive compounds from cactus pear $(O$ ficus-indica), , Vol. 114, pp. 616-622, 2009.

[6] M. Kharidah, A. Hossein, B. Jamilah, Natural colorant and method thereof. Patent WO2010/090508A1, 2009.

[7] S.D. Lim, Y.A. Yusof, N.Y. Chin, T.A. Talib, J. Endan, M.G. Aziz, Effect of extraction parameters on the yield of betacyanins from pitaya fruit ( ) pulps. $J$

, Vol. 9, pp. 158-162, 2011.

[8] Y.Z. Cai, M. Sun, H. Corke, Characterization and application of betalain pigments from plants of the Amaranthaceae.

$$
\text { \& , Vol. 16, pp. 370-376, } 2005
$$

[9] Y.Z. Cai, H. Corke, Production and Properties of Spray-dried Amaranthus Betacyanin Pigments. $J$, Vol. 65, pp. 1248-1252, 2000.

[10] I. Amin, Y. Norazaidah, K.I. Emmy Hainida, Antioxidant activity and phenolic content of raw and branched species. Vol. 94, pp. 47-52, 2006.

[11] K.G.H. Desai, H.J. Park, Recent development in microencapsulation of foods ingredients. Vol. 23, pp. 1361-1394, 2005. temperature of $165.0^{\circ} \mathrm{C}$ with a maltodextrin concentration of $18.84 \%$ exhibited the optimum betacyanin retention, antioxidant activity and $\mathrm{a}^{*}$ value. Thus, as a natural colourant in powder form from , the use of maltodextrin as an encapsulating agent is quite feasible.

\subsection{ACKNOWLEDGEMENT}

The authors would like to thank Universiti Putra Malaysia for Research Grant No. 9378000.
[12] X.D. Chen, M.S. Mujumdar, Drying Technologies in Food Processing, Blackwell Publishing Ltd, UK, 2008.

[13] T.U. Nwabueze, Basic steps in adapting response surface methodology as mathematical modelling for bioprocess optimization in the food systems. $J$

$$
\text { \& , Vol. 45, pp. 1768-1776, } 2010 .
$$

[14] Y.Z. Cai, M. Sun, H.X. Wu, R.H. Huang, H. Corke, Characterization and quantification of betacyanin pigments from diverse species. $J$ \& , Vol. 46, pp. 2063-2070, 1998 b.

[15] D.C. Montgomery, Design and Analysis of Experiments, 7th Edn, John Wiley \& Sons (Asia) Pte Ltd, US, 2009.

[16] R.O. Couto, E.C. Conceicao, L.T. Chaul, E.M.S. Oliveira, F.S. Martins, M.T.F. Bara, K.R. Rezende, S.F. Alves, J.R. Paula, Spray-dried rosemary extracts: Physicochemical and antioxidant properties. ， Vol. 131, pp. 99-105, 2012.

[17] S.Y. Quek, N.K. Chok, P. Swedlund, The physiochemical properties of spray-dried watermelon powders. , Vol. 46, pp. 386-392, 2007.

[18] F.D.B Abadio, A.M. Domingues, S.V. Borges, V.M Oliveira, Physical properties of powdered pineapple ( juice: effect of maltodextrin concentration an atomization speed. J Vol. 64, pp. 285-287, 2004.

[19] G.A. Reiniccius, Multiple-core encapsuation - the spray drying of food ingredients. In: Vilstrup, P. (Ed.), Microencapsulation of Food Ingredients. , pp. 151-185, 2001.

[20] K. Masters, Spray Drying Handbook, 5th Edn. Longman Scientific and Technical, London, 1991.

[21] R.V. Tonon, C. Brabet, M.D. Hubinger, Influence of process conditions on the physicochemical properties of acai ( Mart.) powder produced by spray drying. $J$ , Vol. 88, pp. 411-418, 2008. 


\section{PROFILES}

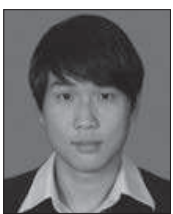

PIK HAN CHONG is a Post-graduate student in the Department of Process and Food Engineering, Faculty of Engineering, Universiti Putra Malaysia, 43400 UPM Serdang, Selangor.

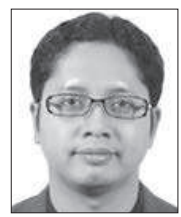

MOHD. NAZLI NAIM is a Senior Lecturer with the Department of Process and Food Engineering, Faculty of Engineering, Universiti Putra Malaysia, 43400 Serdang, Selangor, Malaysia.

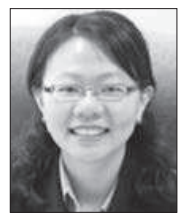

CHIN NYUK LING is an Associate Professor and a Professional Engineer with the Department of Process and Food Engineering, Faculty of Engineering, Universiti Putra Malaysia, 43400 Serdang, Selangor, Malaysia.

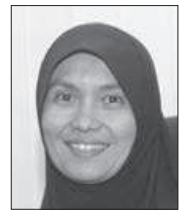

SHARIFAH KHARIDAH SYED MUHAMMAD is an

YUS ANIZA YUSOF is the Head of Department and Associate Professor with the Department of Process and Food Engineering, Faculty of Engineering, Universiti Putra Malaysia, 43400 UPM Serdang, Selangor, Malaysia.
Associate Professor with the Department of Food Science, Faculty of Food Science and Technology, Universiti Putra Malaysia, 43400 Serdang, Selangor, Malaysia. 